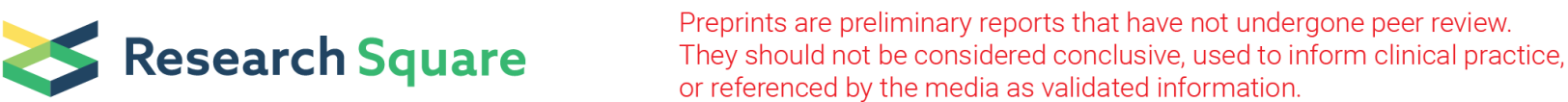

\section{Comparison of Easydo Activator, Ultrasonic and Needle Irrigation Techniques on Sealer Penetration in Extracted Human Teeth}

Li Tan

The Second Xiangya Hospital of Central South University

\section{Ying-Hui Zhou}

The Second Xiangya Hospital of Central South University

\section{Yao Feng}

The Second Xiangya Hospital of Central South University

Qin Ye

The Second Xiangya Hospital of Central South University

Shao-Hui Zhang

The Second Xiangya Hospital of Central South University

\section{Zheng-Rong Gao}

The Second Xiangya Hospital of Central South University

Jie Zhao

The Second Xiangya Hospital of Central South University

\section{Ya-Qiong Zhao}

The Second Xiangya Hospital of Central South University

Jing Hu

The Second Xiangya Hospital of Central South University

\section{Yun Chen}

The Second Xiangya Hospital of Central South University

Qiong Liu

The Second Xiangya Hospital of Central South University

\section{Dusenge Marie Aimee}

The Second Xiangya Hospital of Central South University

\section{Yue Guo}

The Second Xiangya Hospital of Central South University

Yun-Zhi Feng ( $\square$ fengyunzhi001@csu.edu.cn )

The Second Xiangya Hospital of Central South University 
Keywords: Easydo Activator, Ultrasonic, Needle Irrigation Techniques, Sealer Penetration, Extracted Human Teeth

Posted Date: January 5th, 2022

DOI: https://doi.org/10.21203/rs.3.rs-1183156/v1

License: (c) (1) This work is licensed under a Creative Commons Attribution 4.0 International License. Read Full License 


\section{Abstract}

This study compared the effects of different irrigation systems on sealer penetration at the root apex. Forty-two single-rooted teeth were prepared and randomly divided into three groups $(n=14)$ : group 1 : needle irrigation (NI); group 2: passive ultrasonic irrigation (PUI); and group 3: Easydo Activator (EA). A solution of $3 \%$ sodium hypochlorite $(\mathrm{NaOCl})$ was used for irrigation. Nine teeth in each group were filled with AH Plus sealer mixed with CY 5 fluorescent dye and a single gutta-percha cone. The sealer penetration area, maximum penetration depth and percentage of sealer penetration at $5 \mathrm{~mm}$ and $1 \mathrm{~mm}$ from the apex were analyzed by confocal laser scanning microscopy (CLSM). The remaining 5 teeth in each group were subjected to test smear layer scores by scanning electron microscopy (SEM). The CLSM evaluation showed that increases in the area, depth and percentage of sealer penetration were detected at $1 \mathrm{~mm}$ and $5 \mathrm{~mm}$ from the root apex in the PUI group compared with the NI group, and greater increases were observed in the EA group $(P<0.05)$. The SEM experiment showed that the lowest scores for the smear layer and debris removal were achieved by the EA group when compared with the PUI and $\mathrm{NI}$ groups $(P<0.05)$. Our study supports $E A$ was superior to $\mathrm{PUI}$ and $\mathrm{NI}$ regarding sealer penetration at the root apex during endodontic treatment, and it could provide a new technical idea for clinical root canal therapy.

\section{Introduction}

The 3-dimensional filling of the cleaned and shaped root canal system is crucial to the success of root canal treatment $(1,2)$. To enhance the effect of root canal filling, sealers must penetrate into the dentinal tubules (3-5). The residual smear layer produced by mechanical instrumentation can act as a barrier to decrease sealer penetration into the dentinal tubules and might promote bacterial invasion of the dentinal tubules (6-9). Thus, numerous irrigation devices have been developed to remove the smear layer and improve canal cleanliness and filling (10-12).

Conventional needle irrigation $(\mathrm{NI})$ is the most commonly used irrigation technique. However, the application of $\mathrm{NI}$ alone cannot ensure the efficacy of canal preparation because it fails to deliver irrigation solutions 0-2 $\mathrm{mm}$ past the needle tip and into intricate areas of root canals, such as the apical third, where gas particles can become entrapped to produce a vapor lock effect $(13,14)$. Therefore, passive ultrasonic irrigation (PUI) was invented and has proved to be more effective than $\mathrm{NI}$ in removing pulpal tissue remnants and smear layers in the apical third due to its powers of acoustic streaming and cavitation $(15,16)$. However, the effect of removing pulpal tissue remnants and the smear layer using PUI appears to decrease with increasing depth of the root canal system $(17,18)$.

Sonic activation is another irrigation system that uses a mechanical vibration technique for root canal therapy. It is controversial whether this irrigation system can improve root canal cleaning ability and dentinal tubule penetration. In previous studies, sonically activated irrigation needles with the Vibringe System were proved to lead to increased fluid velocity of irrigation, and it could can better remove debris at the apex because of its higher oscillation amplitude at the tip than at the attached end (19). Moreover, 
a similar study reported by Aksel et al. showed that sonically activated NFX irrigation needles using the Vibringe System could better remove smear layer and debris covered or packed into the dentinal tubules, which could lead to better sealer penetration into the dentinal tubules at 1 and $5 \mathrm{~mm}$ from the apex (20). However, other studies have found that the use of sonic activation with the Vibringe System did not significantly improve sealer penetration compared with NI (21). Easydo Activator (EA; Easyinsmile (WEIXIAOMEICHI), Changsha, China) is a new cordless sonic activation device that uses highly flexible polyamide tips with three taper models to deliver irrigants. The highly flexible polyamide tips are soft and flexible and can avoid contact with the canal walls during irrigation, leading to less unintentional dentin removal and increasing sealer penetration. At the same time, the three-dimensional movement of the highly flexible polyamide tips allows EA to efficiently and promptly deliver irrigants into the root canals, particularly in the apical third of the root canal, to achieve prominent cleaning efficiency and improve the success rate of root canal treatment. To the best of our knowledge, the effects of EA on sealer penetration have not been studied.

In this study, we combined confocal laser scanning microscopy (CLSM) and scanning electron microscopy (SEM) methods to evaluate the effect of EA treatments on sealer penetration at the root apex. The usage of these methods both allows for standard and reproducible three-dimensional imaging of the samples (22-24) and provides a comprehensive and detailed analysis of the sealing interface (25-27). The null hypothesis was that there would be no difference in sealer penetration among the three different irrigation techniques.

\section{Materials And Methods}

\subsection{Sample size calculation}

This study was approved by the Institutional Review Board of the Second Xiangya Hospital, Central South University (No. 2021031) and the methods were carried out in accordance with the Declaration of Helsinki (2008). Informed consent was obtained from all patients before sample collection. Sample size calculation was performed with using PASS software (ver. 15.0; NCSS Inc., Kaysville, UT, USA) using the following parameters: two-tailed $5 \%$ significance level $(a=0.05), 95 \%$ confidence interval, $85 \%$ statistical power $(\beta=0.15)$, and a 1:1 ratio of sample allocation in the experimental groups. The minimum sample size for CLSM analysis was calculated to be 9 in each group, while the minimum sample size for SEM analysis was 3 in each group. Thus, the sample size was determined to be 9 in each group for CLSM analysis and 5 in each group for SEM analysis, which was more than or equal to the minimum sample size.

\subsection{Tooth selection and preparation}

Forty-two freshly extracted human mature premolars with a single root canal and no apical absorption were selected for this experiment. Teeth subjected to restorative or endodontic treatment were excluded. Teeth were kept in $0.9 \%$ sodium chloride solution containing $0.02 \%$ sodium azide at $4^{\circ} \mathrm{C}$ to prevent bacterial growth. To standardize canal instrumentation, the crowns of teeth were removed, and the roots 
were set at $12 \mathrm{~mm}$. The working length $(\mathrm{WL})$ of the root canal was determined by subtracting $1 \mathrm{~mm}$ from the distance to the apical foramen. After the apical foramen was filled with light-cured composite resin (Z100, 3M, Saint Paul, MN, USA), canals were prepared by a single operator with No. $10 \mathrm{~K}$ files (Dentsply Maillefer, Ballaigues, Switzerland) and X-Taper Universal files (Easyinsmile, Staten Island, NY, USA) in a crown-down manner to a master apical file size of 30/0.06. During canal preparation, a 30-gauge sidevented needle (Dentsply Tulsa Dental, Tulsa, OK, USA) filled with $2 \mathrm{~mL} \mathrm{3.0 \%} \mathrm{sodium} \mathrm{hypochlorite} \mathrm{(} \mathrm{NaOCl}$ ) solution was used to irrigate the root canals between each file change.

\subsection{Final irrigation procedures}

After completion of the chemomechanical preparation, all specimens were randomly divided into a control group and two experimental groups $(n=42)$ : group 1: $N I(n=14)$; group 2: PUI $(n=14)$; and group 3: EA $(n=14)$. In group 1 , each root canal was irrigated with a continuous flow of $3 \%$ sodium hypochlorite $(\mathrm{NaOCl})(1.5 \mathrm{~mL})$ for 45 seconds within $1 \mathrm{~mm}$ of the WL using a disposable syringe and a 30-gauge sidevented needle (Dentsply Tulsa Dental, Tulsa, OK, USA). Then, $2 \mathrm{~mL}$ of sterilized water were irrigated into the root canal using the same method. In group 2, passive ultrasonic irrigation (PUI, Easyinsmile, Staten Island, NY, USA) with an ultrasonic tip (DTE Endo File; EMS, Nyon, Switzerland) 25/0.04 was placed $1 \mathrm{~mm}$ from the WL at a frequency of $28 \pm 3 \mathrm{kHz}$. An intermittent flush technique was used for the whole irrigation process with a total irrigation volume of $1.5 \mathrm{~mL}$ of $3 \% \mathrm{NaOCl}$ for 3 cycles of 15 seconds. In the intermittent flush technique, the irrigant in a syringe is injected into the root canal and replenished after each ultrasonic activation cycle several times. In group 3, EA (Easyinsmile (WEIXIAOMEICHI), Changsha, China) with a 25/0.04 EA tip was placed $1 \mathrm{~mm}$ short of the WL at a frequency of $3 \mathrm{kHz}$ (2 gear powers) to deliver $3 \% \mathrm{NaOCl}(1.5 \mathrm{~mL})$ for 45 seconds. After each respective irrigant, all root canals were dried with paper points.

\subsection{CLSM preparation and analysis}

Nine teeth in each group were sealed with AH Plus sealer (Dentsply, DeTrey, Konstanz, Germany) mixed with CY5 fluorescent dye (Bereket Chemical Industry, Istanbul, Turkey) and a single gutta-percha cone (ProTaper Universal F4, Dentsply Maillefer, Ballaigues, Switzerland). A \#25.02 Lentulo spiral (Dentsply Maillefer, Ballaigues, Switzerland) attached to a handpiece at 20,000 rpm was inserted into the canal for 5 seconds to allow the sealer to be placed $1 \mathrm{~mm}$ short of the WL. After root filling, the coronal access was filled with temporary filling material (Cavit G, 3M; ESPE, St. Paul, MN, USA), and then specimens were stored in an incubator at $100 \%$ humidity and $37^{\circ} \mathrm{C}$ for 1 week for the next CLSM analysis.

Then, each sample was sectioned perpendicular to the long axis using a precision saw (EXAKT $300 \mathrm{CP}$; EXAKT, Norderstedt, Germany). Three slices were obtained from each tooth at depths of $5 \mathrm{~mm}$ and $1 \mathrm{~mm}$ and approximately $1 \pm 0.1 \mathrm{~mm}$ in thickness. The sections were polished with an EXAKT grinder (EXAKT 400 CS; EXAKT, Norderstedt, Germany). The samples were then mounted onto glass slides and examined with confocal laser scanning microscopy (LSM800; ZEISS, Jena, Germany) at $\times 10$ magnification with a wavelength of $560-600 \mathrm{~nm}$. 
Digital images were imported into ImageJ software (ImageJ 2x, Rawak Software Inc., Stuttgart, Germany). The sealer penetration area was measured in micrometers and converted to square millimeters for statistical analysis. To determine the maximum depth of penetration, the point of deepest penetration was measured from the canal wall to the point of maximum sealer penetration. The proportion of the root canal wall was measured, and areas along the canal walls into which the sealer penetrated the dentinal tubules at any distance were calculated. The outlined areas were divided by the canal proportion to calculate the percentage of sealer penetration.

\subsection{SEM preparation and analysis}

To describe the effect of the final irrigation protocol on the removal of debris and smear layer from root canal walls, five samples from each group were prepared for scanning electron microscopy (SEM). Every sample was separated longitudinally in the buccolingual direction using a bone hammer and bone chisels as reported by Shu Wan (28). The more complete half was selected. Horizontal marks were made at the apical sections on the cut/split dentin surface outside the root canal using a sharp scalpel. The samples were dried, mounted on metallic stubs, and examined under SEM (JSM-IT100; Jeol, Tokyo, Japan) at $10 \mathrm{kV}$. Photomicrographs at the apical thirds of each specimen were obtained at $\times 500$ and $\times 1000$. The images at $\times 1000$ were used for smear layer evaluation. The images were evaluated by two practitioners who were blinded to group assignment and final irrigation procedures. The analysis was performed according to the four-level scoring system of Akyuz Ekim et al. (29); Score 1: no smear layer or debris evidence on the dentinal tubules; Score 2: a few regions of the dentinal tubules covered with a smear layer and debris, with most tubules cleaned and opened; Score 3: most regions of the dentinal tubules covered with a smear layer and debris, with a few tubules cleaned and opened; and Score 4: the dentinal tubules completely covered with smear layer and debris. Practitioners were previously calibrated for the scoring system to ensure interexaminer agreement. After achieving a good level of agreement (kappa $\geq 0.75$ ), the practitioners scored the images independently. The kappa value in this study was 0.821 . The Kruskal-Wallis test (Mann-Whitney U post hoc test) was used to analyze the scores at the significance level of $5 \%$.

\subsection{Statistical analysis}

All of the data were analyzed using SPSS software (SPSS Statistics, version 23.0; SPSS Inc., IBM, Armonk, NY, USA). The CLSM data were calculated and expressed as the mean, median, standard deviation (SD), minimum, and maximum and evaluated using analysis of variance (ANOVA) with least significance difference (LSD) tests. The SEM data were calculated and expressed as the median and SD and analyzed using ANOVA with the LSD test. A $P$ value of 0.05 was considered statistically significant. GraphPad Prism software (GPW5-384305-RAG-5235, version 5.01; GraphPad Software Inc., San Diego, CA, USA) was used to draw diagrams.

\section{Results}

\subsection{CLSM analysis}


Figure 1 shows representative CLSM images of each group at both $5 \mathrm{~mm}$ and $1 \mathrm{~mm}$ from the apex. The sealer penetration area $\left(\mathrm{mm}^{2}\right)$, maximum penetration depth $(\mathrm{mm})$ and percentage of sealer penetration (\%) of each group at $5 \mathrm{~mm}$ and $1 \mathrm{~mm}$ from the apex are summarized in Tables 1 and 2, showing the mean, median, standard deviation, minimum, and maximum. The mean and SD of these results are shown in column diagrams in Fig. 2(A), 2(B) and 2(C).

\section{Table 1}

Sealer penetration area $\left(\mathrm{mm}^{2}\right)$, depth $(\mathrm{mm})$, and percentage $(\%)$ of the test groups at $5 \mathrm{~mm}$ from the apex.

\begin{tabular}{|c|c|c|c|c|c|c|c|}
\hline Group & $5 \mathrm{~mm}$ & No. & Mean & Median & $\begin{array}{l}\text { Standard } \\
\text { deviation }\end{array}$ & Minimum & Maximum \\
\hline \multirow{3}{*}{$\begin{array}{l}\text { Group } 1 \\
\text { Needle } \\
\text { Irrigation }\end{array}$} & Area $^{+}$ & 9 & 0.757 & 0.666 & 0.194 & 0.558 & 1.071 \\
\hline & Depth $^{\dagger}$ & 9 & 0.282 & 0.278 & 1.135 & 0.131 & 0.444 \\
\hline & Percentage $^{\dagger}$ & 9 & 10.75 & 10.92 & 2.42 & 7.74 & 14.37 \\
\hline \multirow{3}{*}{$\begin{array}{l}\text { Group } 2 \\
\text { Passive } \\
\text { ultrasonic } \\
\text { irrigation }\end{array}$} & Area $^{\ddagger}$ & 9 & 1.738 & 1.638 & 0.861 & 0.594 & 3.348 \\
\hline & Depth $^{\ddagger}$ & 9 & 1.024 & 1.035 & 0.108 & 0.780 & 1.160 \\
\hline & Percentage $\mathrm{e}^{\ddagger}$ & 9 & 32.14 & 30.79 & 4.70 & 25.44 & 39.19 \\
\hline \multirow{3}{*}{$\begin{array}{l}\text { Group } 3 \\
\text { Easydo Activator }\end{array}$} & Area $^{\ddagger}$ & 9 & 2.243 & 2.079 & 0.574 & 1.629 & 3.105 \\
\hline & Depth§ & 9 & 1.327 & 1.400 & 0.303 & 0.846 & 1.680 \\
\hline & Percentage $§$ & 9 & 48.51 & 44.35 & 11.45 & 34.39 & 65.63 \\
\hline
\end{tabular}


Table 2

Sealer penetration area $\left(\mathrm{mm}^{2}\right)$, depth $(\mathrm{mm})$, and percentage $(\%)$ of the test groups at $1 \mathrm{~mm}$ from the apex.

\begin{tabular}{|c|c|c|c|c|c|c|c|}
\hline Group & $1 \mathrm{~mm}$ & No. & Mean & Median & $\begin{array}{l}\text { Standard } \\
\text { deviation }\end{array}$ & Minimum & Maximum \\
\hline \multirow{3}{*}{$\begin{array}{l}\text { Group } 1 \\
\text { Needle } \\
\text { Irrigation }\end{array}$} & Area $^{\dagger}$ & 9 & 0.511 & 0.468 & 0.122 & 0.396 & 0.792 \\
\hline & Depth $^{\dagger}$ & 9 & 0.182 & 0.191 & 0.047 & 0.094 & 0.238 \\
\hline & Percentage $^{\dagger}$ & 9 & 7.64 & 7.54 & 0.63 & 6.79 & 8.44 \\
\hline \multirow{3}{*}{$\begin{array}{l}\text { Group } 2 \\
\text { Passive } \\
\text { ultrasonic } \\
\text { irrigation }\end{array}$} & Area $^{\dagger}$ & 9 & 0.707 & 0.630 & 0.235 & 0.432 & 1.188 \\
\hline & Depth $^{\ddagger}$ & 9 & 0.391 & 0.354 & 0.073 & 0.297 & 0.532 \\
\hline & Percentage $\mathrm{e}^{\ddagger}$ & 9 & 14.57 & 15.12 & 2.33 & 10.62 & 17.35 \\
\hline \multirow{3}{*}{$\begin{array}{l}\text { Group } 3 \\
\text { Easydo Activator }\end{array}$} & Area§ & 9 & 2.069 & 1.890 & 0.650 & 1.485 & 3.519 \\
\hline & Depth§ & 9 & 0.726 & 0.659 & 0.163 & 0.574 & 1.079 \\
\hline & Percentage $\S$ & 9 & 45.94 & 45.73 & 12.37 & 34.15 & 74.33 \\
\hline
\end{tabular}

\subsubsection{Mean penetration area}

The sealer penetration areas at $5 \mathrm{~mm}$ from the apex in the $\mathrm{NI}$ and PUl groups were larger than that at 1 $\mathrm{mm}$ at the root canal level $(P<0.05)$, whereas no significant difference was observed in the EA group. EA and PUI increased the sealer penetration area more than $\mathrm{Nl}$ at the $5 \mathrm{~mm}$ level $(P<0.05)$. There was no significant difference between the $\mathrm{NI}$ and $\mathrm{PUI}$ groups at $1 \mathrm{~mm}$ from the apex regarding the penetration area $(P>0.05)$. Activation with the EA instrument $\left(2.069 \pm 0.650 \mathrm{~mm}^{2}\right)$ promoted more sealer penetration area at $1-\mathrm{mm}$ root level compared to the other groups $(P<0.05)$.

\subsubsection{Maximum penetration depth}

The sealer penetration depth from the apical $5 \mathrm{~mm}$ was greater than that from the apical $1 \mathrm{~mm}$ in each group $(P<0.05)$. There were great differences in sealer penetration depth among different groups. The EA group $(1.327 \pm 0.303 \mathrm{~mm}$ at $5 \mathrm{~mm}, 0.726 \pm 0.163 \mathrm{~mm}$ at $1 \mathrm{~mm})$ was better than the PUl group $(1.024 \pm$ $0.108 \mathrm{~mm}$ at $5 \mathrm{~mm}, 0.391 \pm 0.073 \mathrm{~mm}$ at $1 \mathrm{~mm})$, and the PUl group was better than the $\mathrm{NI}$ group $(P<$ 0.05).

\subsubsection{Percentage of sealer penetration}


The difference in the percentage of sealer penetration between $5 \mathrm{~mm}$ and $1 \mathrm{~mm}$ from the apex was not statistically significant in the EA group ( $48.51 \pm 11.45 \%$ at $5 \mathrm{~mm}, 45.94 \pm 12.37 \%$ at $1 \mathrm{~mm} ; P \otimes 0.05)$, while the NI group and PUl group had a higher percentage of sealer penetration at the 5 -mm level $(10.75 \pm$ $2.42 \%$ in $\mathrm{NI}, 32.14 \pm 4.70 \%$ in PUI) than that in the 1-mm level $(7.64 \pm 0.63 \%$ in $\mathrm{NI}, 14.57 \pm 2.33 \%$ in PUl; $P<$ 0.05). Large differences were found in the percentage of sealer penetration among the groups using different irrigating instruments $(P<0.05)$. The sealer infiltration percentage was significantly increased by EA compared with PUI and $\mathrm{NI}(P<0.05)$.

\subsection{SEM analysis}

Figure 3 shows representative SEM images at $\times 500$ and $\times 1000$ of each group from the apex. The EA group (Fig. 3c, f) presented a smaller smear layer and debris covering the surface of dentinal tubules than the PUl group (Fig. 3b, e), and PUI (Fig. 3b, e) presented less smear layer and debris covering the surface of the dentinal tubules than $\mathrm{NI}$ (Fig. 3a, d). The results of the evaluated smear layer scores are summarized in Table 3, showing the mean and standard deviation. The smear layer score of the EA group $(1.200 \pm 0.447)$ was lower than that of the PUI group $(2.600 \pm 0.548 ; P<0.05)$, and the smear layer score of the PUl group was lower than that of the NI group $(3.600 \pm 0.548 ; P<0.05)$.

Table 3

Smear layer scores of the test groups at the apical third of the root canal.

\begin{tabular}{|lccl|}
\hline Group & No. & Mean & Standard deviation \\
\hline $\begin{array}{l}\text { Group } 1 \\
\text { Needle Irrigation }\end{array}$ & 5 & $3.600^{\dagger}$ & 0.548 \\
\hline $\begin{array}{l}\text { Group2 } \\
\text { Passive ultrasonic irrigation }\end{array}$ & 5 & $2.600^{\ddagger}$ & 0.548 \\
Group 3 & 5 & $1.200 \S$ & 0.447 \\
Easydo Activator & & & \\
\hline $\begin{array}{l}\text { Different letters indicate a significant difference at the } \\
\text { same superscript are not significantly different.) }\end{array}$ & & \\
\hline
\end{tabular}

\section{Discussion}

Removal of the smear layer from the canal walls during instrumentation allows for access of endodontic irrigants and sealers into the dentinal tubules $(30,31)$. The EA instrument used in our study is a new cordless sonic activation device that uses highly flexible polyamide tips with three taper models, and it is soft and flexible so that it can efficiently and promptly irrigate the root canals with less contact with the canal walls. Nonetheless, further research is warranted to provide a more detailed understanding of the cleaning efficiency of EA tips at the apex. The aim of this in vitro study was to evaluate the effects of 
different irrigation systems on AH Plus sealer penetration into the dentinal tubules by CLSM. Then, the removal of the smear layer was observed by SEM to confirm these findings.

The CLSM evaluation showed that, at $5 \mathrm{~mm}$ from the apex, EA and PUl exhibited greater penetration area, penetration depth and percentage of sealer penetration than $\mathrm{NI}(P<0.05)$, in agreement with previous research by de Gregorio et al, who found that sonic activation devices (EndoActivator) and PUI have better sealer penetration than $\mathrm{NI}$ in the apical third (at $4.5 \mathrm{~mm}$ from WL) (32). It has been reported that the main reason why EA and PUI have better sealer penetration than $\mathrm{NI}$ is that they increase the irrigant flow rate using different oscillation patterns $(14,33)$, which can better reduce vapor lock in the apical third of the root canal during irrigation $(34,35)$.

Moreover, markedly more sealer penetration was found at the level of $1 \mathrm{~mm}$ for EA than for PUI and $\mathrm{NI}(P$ $<0.05)$ in the evaluation of CLSM In addition, sealer penetration was decreased in the $\mathrm{NI}$ and PUI groups at $1 \mathrm{~mm}$ from the apex compared with that at $5 \mathrm{~mm}$ from the apex, whereas sealer penetration was not significantly decreased in the EA group (except for the penetration depth). In our study, EA uses a mechanical vibration technique that works at a frequency of $3 \mathrm{kHz}$ and an amplitude of $150 \mu \mathrm{m}$, while the ultrasonic tip in PUI has a high frequency of approximately $28-32 \mathrm{kHz}$ and amplitude of $28 \mu \mathrm{m}$ (36). Previous studies have shown that, in the apical third of the root canal, the oscillation amplitude could have a greater effect on the penetration of sealers and irrigants than the oscillation frequency $(36,37)$. Therefore, we believe that one reason why EA has better sealer penetration at $1 \mathrm{~mm}$ from the apex than PUI is that the oscillation amplitude of EA is higher than that of PUI, even if the oscillation frequency of EA is lower than that of PUl. Another reason for markedly more sealer penetration at $1 \mathrm{~mm}$ from the apex found with EA than with PUI might be that, during irrigation, the amplitude of EA did not obviously change because the vibratory flexible polyamide tip is soft and flexible and has less contact with the root canal walls. In contrast, the ultrasonic tip of PUl is made of a rigid metal and can easily contact the canal walls when oscillating, which might sharply reduce the amplitude of the tip during irrigation $(38,39)$. The higher and nonweakened oscillation amplitude in EA produces a higher irrigant flow rate, which has been reported to eliminate vapor lock and enhance sealer penetration (37).

Although the sonic activation device has a higher oscillation amplitude, it is puzzling that some studies have shown that sonic activation devices did not significantly improve sealer penetration at the root apex compared with $\mathrm{NI}$ irrigation and PUI $(21,40)$. This different might be due to lower acoustic streaming generated by the sonic activation device with a small preparation taper size. Acoustic streaming is a very important factor for increasing the penetration of irrigants or sealers into dentinal tubules at the root apex (41). If the preparation taper size is too small, the ability of the sonic activation device to generate acoustic streaming will be weaker because the capability of this device to generate acoustic streaming is based on the wide displacement amplitude of its tip, thus leading to a reduction in the penetration of irrigants or sealers into the dentinal tubules. In contrast, the acoustic streaming activated by PUI is minimally affected by the preparation taper size because PUI mainly activates acoustic streaming through a high vibration frequency rather than relying on a wide displacement amplitude (42). The preparation taper size in our study (30/0.06) was larger than that used in the previous study $(30 / 0.04)$ 
(42), which might be one reason why the EA group had more sealer penetration than the PUI group at the root apex. Our study also indicated that a 30/0.06 taper might be sufficient for EA to generate sufficient acoustic streaming to result in better sealer penetration at the root apex.

Consistent with a previous study, we further verified that PUI had greater ability to remove the smear layer than $\mathrm{NI}$ in the apical third through SEM experiments because its high driving frequency of ultrasound (30 $\mathrm{kHz}$ ) can lead to a high flow velocity of irrigant, resulting in more effective delivery of irrigant to the apical third of the root canal $(19,35)$. Moreover, we found that EA could more effectively remove the smear layer and debris than PUI and NI. This finding is not surprising because the tip of the EA had a higher oscillation amplitude, which could increase the flow velocity of the irrigant, thus achieving better removal of the smear layer in the apical third than PUI (39). In addition, the sonic tip made of flexible polyamide could prevent the root canal dentin wall from cutting, resulting in less smear layer being produced in the canal dentin wall (43). Since the residual smear layer produced by mechanical instrumentation can act as a barrier to decrease sealer penetration (6-9), the SEM finding that EA can effectively remove the smear layer was consistent with the CLSM findings. Thus, the present study data rejected the null hypothesis that there would be no differences in sealer penetration among the three different irrigation techniques.

In conclusion, the present study showed that EA was superior to PUI and $\mathrm{NI}$ in straight root canals regarding sealer penetration at the apical third of the root canal. This outcome suggests that EA is a promising irrigation device to increase sealer penetration, which could be a crucial factor for the success of root canal treatment.

\section{Declarations}

\section{Data availability}

The datasets generated during and/or analyzed during the current study are available from the corresponding author on reasonable request.

\section{Acknowledgments}

The authors would like to thank the Easyinsmile (Changsha, China) Company for this research. National Natural Science Foundation of China (grant nos. 81773339 and 81800788) for support, the Science and Technology Department of Hunan Province, China (grant nos. 2017WK2041 and 2018SK52511), the fund for Xiangya Clinical Medicine Database of Central South University (grant no. 2014-ZDYZ-1-16), and the Open Sharing Fund for the Large-scale Instruments and Equipment of Central South University.

\section{Author contributions}


L.T., Y.C., J.H., Y.F., Q.Y., and L.Q. performed experiments, designed and supervised experiments, analyzed data and co-wrote the manuscript. Y.-H.Z., S.-H.Z., Z.-R.G., and Y.-Q.Z. performed experiments and collected data. J.Z. and D.A. designed and supervised experiments, analyzed data, and wrote the manuscript. Y.G. and Y.-Z.F. provided conceptual input and edited the manuscript. All authors reviewed the manuscript.

\section{Competing interests}

The authors declare that they have no competing interests.

\section{Additional information}

Correspondence and requests for materials should be addressed to Y.G. and Y.-Z.F.

Reprints and permissions information is available at www.nature.com/reprints. Publisher's note Springer Nature remains neutral with regard to jurisdictional claims in published maps and institutional afliations.

\section{References}

1. Gillen, B. et al. Impact of the quality of coronal restoration versus the quality of root canal fillings on success of root canal treatment: a systematic review and meta-analysis. Journal of endodontics 37 , 895-902, https://doi.org/10.1016/j.joen.2011.04.002 (2011).

2. Gunes, B., Yeter, K., Terlemez, A., Seker, B. \& Altay, Y. Dentinal tubule penetration of endodontic sealers after nonthermal plasma treatment: A confocal laser scanning microscopy study. Microscopy research and technique 82, 903-908, https://doi.org/10.1002/jemt.23237 (2019).

3. Cergneux, M., Ciucchi, B., Dietschi, J. \& Holz, J. The influence of the smear layer on the sealing ability of canal obturation. International endodontic journa/ 20, 228-232, https://doi.org/10.1111/j.13652591.1987.tb00619.x (1987).

4. Lone, M., Khan, F. \& Lone, M. Evaluation of Microleakage in Single-Rooted Teeth Obturated with Thermoplasticized Gutta-Percha Using Various Endodontic Sealers: An In-Vitro Study. Journal of the College of Physicians and Surgeons-Pakistan: JCPSP 28, 339-343, https://doi.org/10.29271/jcpsp.2018.05.339 (2018).

5. Ma, X. et al. Materials for retrograde filling in root canal therapy. The Cochrane database of systematic reviews 12, CD005517, https://doi.org/10.1002/14651858.CD005517.pub2 (2016).

6. Zancan, R., Di Maio, A., Tomson, P., Duarte, M. \& Camilleri, J. The presence of smear layer affects the antimicrobial action of root canal sealers. International endodontic journal 54, 1369-1382, https://doi.org/10.1111/jej.13522 (2021).

7. Candeiro, G. et al. Penetration of bioceramic and epoxy-resin endodontic cements into lateral canals. Brazilian oral research 33, https://doi.org/10.1590/1807-3107bor-2019.vol33.0049 (2019). 
8. Del Fabbro, M. et al. Endodontic procedures for retreatment of periapical lesions. Cochrane Database Syst Rev 10, Cd005511, https://doi.org/10.1002/14651858.CD005511.pub3 (2016).

9. Economides, N., Liolios, E., Kolokuris, I. \& Beltes, P. Long-term evaluation of the influence of smear layer removal on the sealing ability of different sealers. J Endod 25, 123-125, https://doi.org/10.1016/s0099-2399(99)80010-7 (1999).

10. Ballal, V., Rao, S., Al-Haj Husain, N. \& Özcan, M. Evaluation of Smear Layer Removal Using Different Irrigation Methods In Root Canals. Eur J Prosthodont Restor Dent 27, 97-102, https://doi.org/10.1922/EJPRD_01817Husain06 (2019).

11. Buldur, B. \& Kapdan, A. Comparison of the EndoVac system and conventional needle irrigation on removal of the smear layer in primary molar root canals. Niger J Clin Pract 20, 1168-1174, https://doi.org/10.4103/1119-3077.181351 (2017).

12. Mohammadi, Z. et al. Smear Layer Removing Ability of Root Canal Irrigation Solutions: A Review. J Contemp Dent Pract 20, 395-402 (2019).

13. Virdee, S. S., Seymour, D. W., Farnell, D., Bhamra, G. \& Bhakta, S. Efficacy of irrigant activation techniques in removing intracanal smear layer and debris from mature permanent teeth: a systematic review and meta-analysis. Int Endod J 51, 605-621, https://doi.org/10.1111/iej.12877 (2018).

14. Timpawat, S., Vongsavan, N. \& Messer, H. H. Effect of removal of the smear layer on apical microleakage. J Endod 27, 351-353, https://doi.org/10.1097/00004770-200105000-00011 (2001).

15. van der Sluis, L. W., Versluis, M., Wu, M. K. \& Wesselink, P. R. Passive ultrasonic irrigation of the root canal: a review of the literature. Int Endod J 40, 415-426, https://doi.org/10.1111/j.13652591.2007.01243.x (2007).

16. Moreira, R. N., Pinto, E. B., Galo, R., Falci, S. G. M. \& Mesquita, A. T. Passive ultrasonic irrigation in root canal: systematic review and meta-analysis. Acta Odontol Scand 77, 55-60, https://doi.org/10.1080/00016357.2018.1499960 (2019).

17. Plotino, G. et al. Evaluation of smear layer and debris removal by stepwise intraoperative activation (SIA) of sodium hypochlorite. Clin Oral Investig 25, 237-245, https://doi.org/10.1007/s00784-02003358-6 (2021).

18. Blank-Gonçalves, L. M., Nabeshima, C. K., Martins, G. H. \& Machado, M. E. Qualitative analysis of the removal of the smear layer in the apical third of curved roots: conventional irrigation versus activation systems. J Endod 37, 1268-1271, https://doi.org/10.1016/j.joen.2011.06.009 (2011).

19. Rödig, T., Bozkurt, M., Konietschke, F. \& Hülsmann, M. Comparison of the Vibringe system with syringe and passive ultrasonic irrigation in removing debris from simulated root canal irregularities. $J$ Endod 36, 1410-1413, https://doi.org/10.1016/j.joen.2010.04.023 (2010).

20. Aksel, H., Küçükkaya Eren, S. \& Serper, A. Comparison of triple antibiotic paste removal by different irrigation techniques. Dent Mater J 36, 303-308, https://doi.org/10.4012/dmj.2016-105 (2017).

21. Bolles, J. A., He, J., Svoboda, K. K., Schneiderman, E. \& Glickman, G. N. Comparison of Vibringe, EndoActivator, and needle irrigation on sealer penetration in extracted human teeth. J Endod 39, 
708-711, https://doi.org/10.1016/j.joen.2013.01.006 (2013).

22. De-Deus, G. et al. Lack of correlation between sealer penetration into dentinal tubules and sealability in nonbonded root fillings. Int Endod J 45, 642-651, https://doi.org/10.1111/j.13652591.2012.02023.x (2012).

23. Akcay, M., Arslan, H., Durmus, N., Mese, M. \& Capar, I. D. Dentinal tubule penetration of AH Plus, iRoot SP, MTA fillapex, and guttaflow bioseal root canal sealers after different final irrigation procedures: A confocal microscopic study. Lasers Surg Med 48, 70-76, https://doi.org/10.1002/lsm.22446 (2016).

24. Gharib, S. R., Tordik, P. A., Imamura, G. M., Baginski, T. A. \& Goodell, G. G. A confocal laser scanning microscope investigation of the epiphany obturation system. J Endod 33, 957-961, https://doi.org/10.1016/j.joen.2007.03.011 (2007).

25. Gomes, G. M. et al. Influence of the resin cement thickness on bond strength and gap formation of fiber posts bonded to root dentin. J Adhes Dent 16, 71-78, https://doi.org/10.3290/j.jad.a30878 (2014).

26. Haupt, F., Meinel, M., Gunawardana, A. \& Hülsmann, M. Effectiveness of different activated irrigation techniques on debris and smear layer removal from curved root canals: a SEM evaluation. Aust Endod J 46, 40-46, https://doi.org/10.1111/aej.12342 (2020).

27. Saghiri, M. A. et al. Back-scattered and secondary electron images of scanning electron microscopy in dentistry: a new method for surface analysis. Acta Odontol Scand 70, 603-609, https://doi.org/10.3109/00016357.2011.645057 (2012).

28. Wan, S., Tan, Y., Xie, J., Huang, X. \& Guo, L. The effect of a root-dentin pretreatment technique combining PIPS with MTAD aiming to improve the bond strength of glass fiber post. Microsc Res Tech 83, 824-833, https://doi.org/10.1002/jemt.23474 (2020).

29. Akyuz Ekim, S. N. \& Erdemir, A. Comparison of different irrigation activation techniques on smear layer removal: an in vitro study. Microsc Res Tech 78, 230-239, https://doi.org/10.1002/jemt.22466 (2015).

30. Neelakantan, P., Ounsi, H. F., Devaraj, S., Cheung, G. S. P. \& Grandini, S. Effectiveness of irrigation strategies on the removal of the smear layer from root canal dentin. Odontology 107, 142-149, https://doi.org/10.1007/s10266-018-0373-2 (2019).

31. Paragliola, R. et al. Final rinse optimization: influence of different agitation protocols. J Endod 36, 282-285, https://doi.org/10.1016/j.joen.2009.10.004 (2010).

32. de Gregorio, C., Estevez, R., Cisneros, R., Heilborn, C. \& Cohenca, N. Effect of EDTA, sonic, and ultrasonic activation on the penetration of sodium hypochlorite into simulated lateral canals: an in vitro study. J Endod 35, 891-895, https://doi.org/10.1016/j.joen.2009.03.015 (2009).

33. Dioguardi, M. et al. Endodontic irrigants: Different methods to improve efficacy and related problems. Eur J Dent 12, 459-466, https://doi.org/10.4103/ejd.ejd_56_18 (2018).

34. Boutsioukis, C. et al. Formation and removal of apical vapor lock during syringe irrigation: a combined experimental and Computational Fluid Dynamics approach. Int Endod J 47, 191-201, https://doi.org/10.1111/iej.12133 (2014). 
35. Jiang, L. M., Verhaagen, B., Versluis, M. \& van der Sluis, L. W. Evaluation of a sonic device designed to activate irrigant in the root canal. $J$ Endod 36, 143-146, https://doi.org/10.1016/j.joen.2009.06.009 (2010).

36. Tungsawat, P. et al. Comparison of the Effect of Three Irrigation Techniques and Root Canal Preparation Size on Sodium Hypochlorite Penetration into Root Canal Dentinal Tubules. Int J Dent 2021, 6612588, https://doi.org/10.1155/2021/6612588 (2021).

37. Boutsioukis, C. et al. Formation and removal of apical vapor lock during syringe irrigation: a combined experimental and Computational Fluid Dynamics approach. Int Endod J 47, 191-201, https://doi.org/10.1111/iej.12133 (2014).

38. Urban, K., Donnermeyer, D., Schäfer, E. \& Bürklein, S. Canal cleanliness using different irrigation activation systems: a SEM evaluation. Clin Oral Investig 21, 2681-2687, https://doi.org/10.1007/s00784-017-2070-x (2017).

39. Agarwal, A. et al. Evaluation of Apical Vapor Lock Formation and comparative Evaluation of its Elimination using Three different Techniques: An in vitro Study. J Contemp Dent Pract 18, 790-794, https://doi.org/10.5005/jp-journals-10024-2128 (2017).

40. Aksel, H., Küçükkaya Eren, S., Puralı, N., Serper, A. \& Azim, A. A. Effıcacy of different irrigant protocols and application systems on sealer penetration using a stepwise CLSM analysis. Microsc Res Tech 80, https://doi.org/10.1002/jemt.22944 (2017).

41. Ahmad, M., Pitt Ford, T. R., Crum, L. A. \& Walton, A. J. Ultrasonic debridement of root canals: acoustic cavitation and its relevance. J Endod 14, 486-493, https://doi.org/10.1016/S0099-2399(88)80105-5 (1988).

42. Merino, A., Estevez, R., de Gregorio, C. \& Cohenca, N. The effect of different taper preparations on the ability of sonic and passive ultrasonic irrigation to reach the working length in curved canals. Int Endod J 46, 427-433, https://doi.org/10.1111/iej.12006 (2013).

43. Zeng, C. et al. Antibacterial efficacy of an endodontic sonic-powered irrigation system: An in vitro study. J Dent 75, 105-112, https://doi.org/10.1016/j.jdent.2018.06.003 (2018).

\section{Figures}


Fig. 1

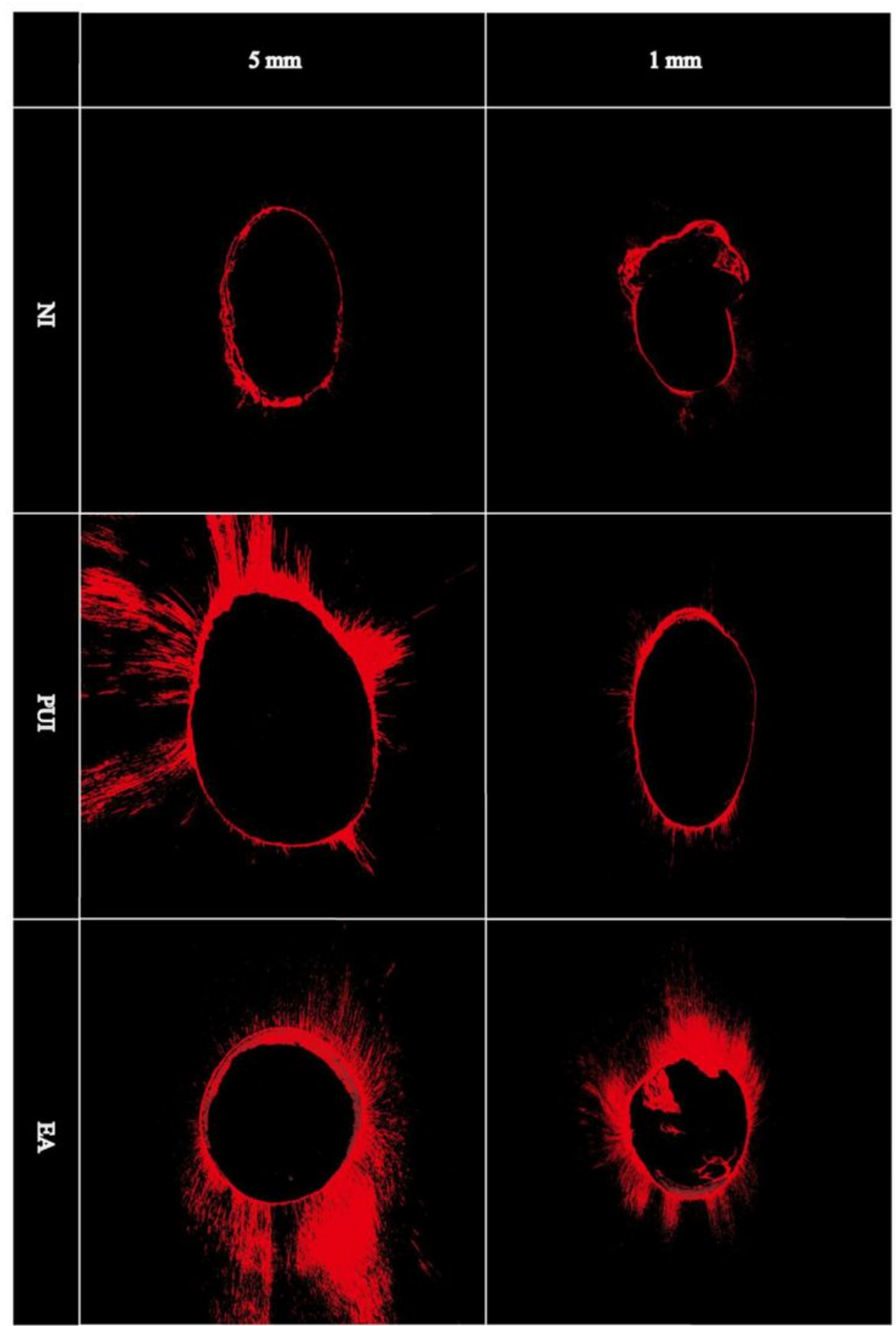

\section{Figure 1}

Representative CLSM images of each group at both $5 \mathrm{~mm}$ and $1 \mathrm{~mm}$ from the apex. (CLSM, confocal laser scanning microscopy; $\mathrm{NI}$, needle irrigation; PUI, passive ultrasonic irrigation; EA, Easydo Activator.) 
Fig. 2
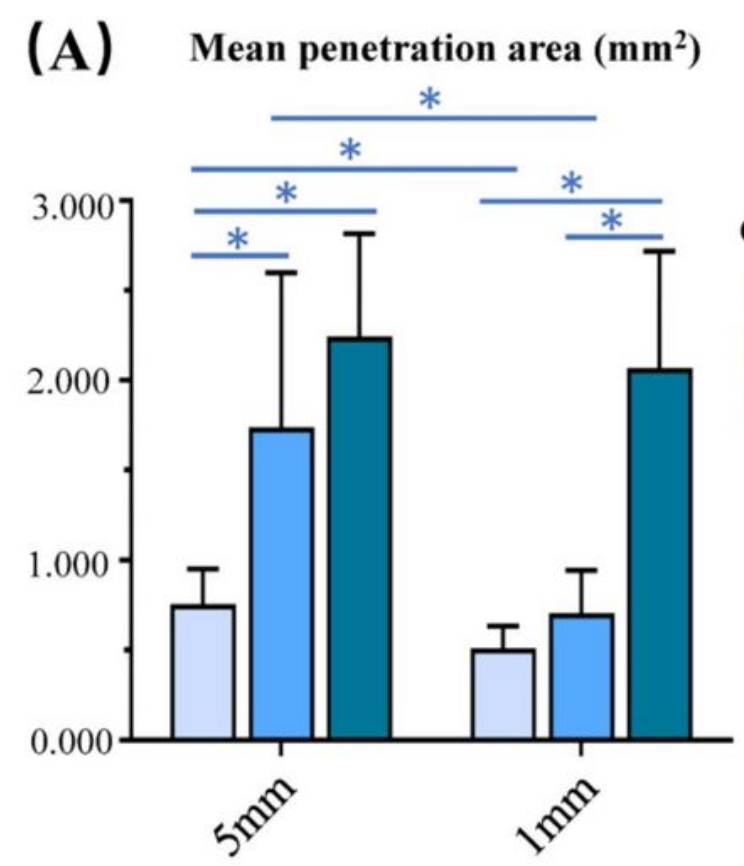

(B) Maximum penetration depth (mm)

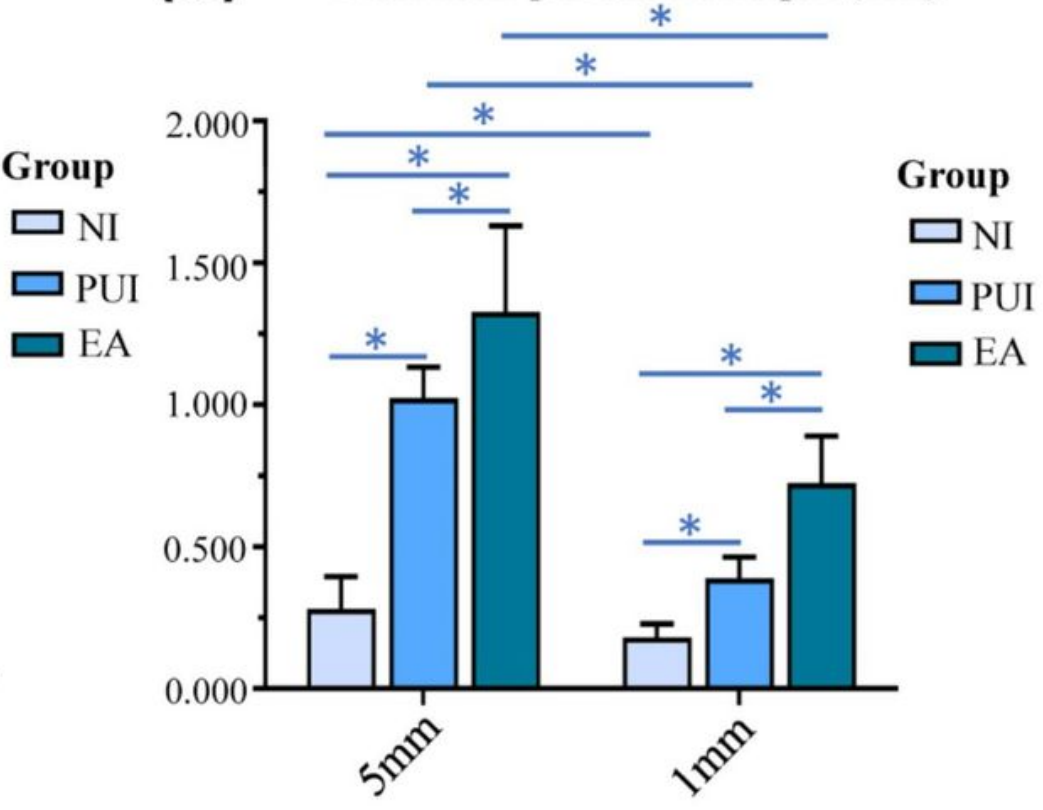

(C) Percent of sealer penetration (\%)

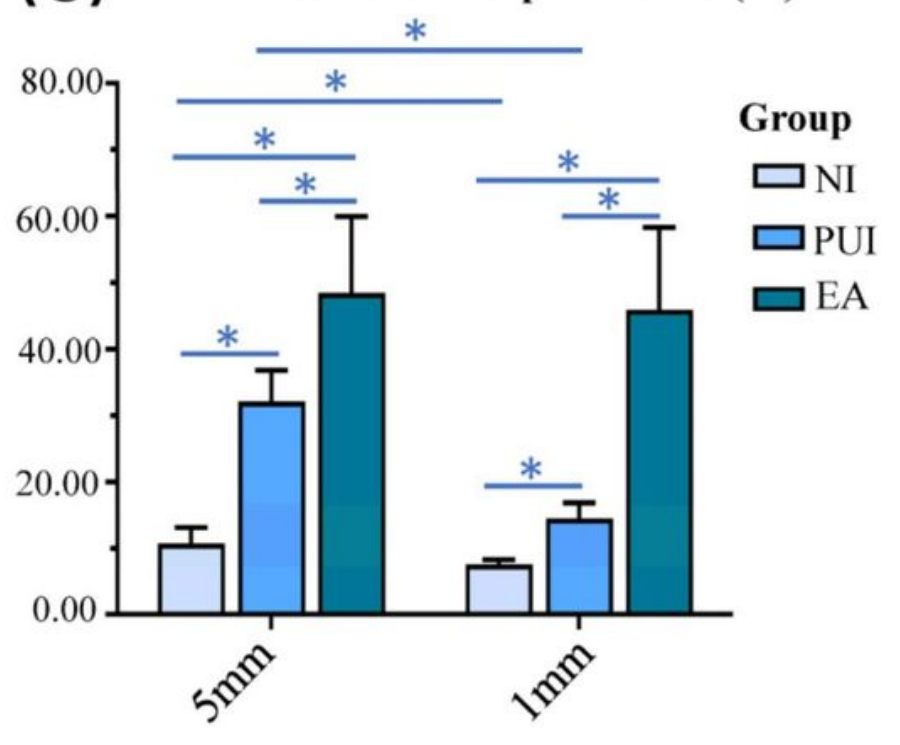

\section{Figure 2}

Column diagrams showing the mean \pm SD of the mean penetration area (a), maximum penetration depth (b) and percentage of sealer penetration (c) for test groups at the levels of $5 \mathrm{~mm}$ and $1 \mathrm{~mm}$ from the apex. $\left(^{\star}\right)$ indicates a significant difference at the $5 \%$ significance level $(P<0.05)$. ( $\mathrm{NI}$, needle irrigation; PUI, passive ultrasonic irrigation; EA, Easydo Activator.) 
Fig. 3

NI
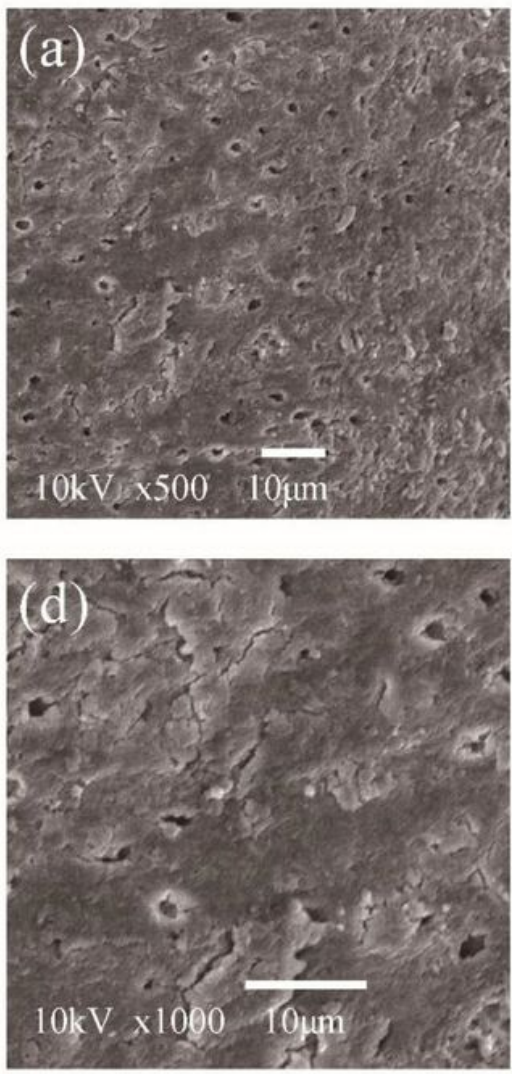

PUI
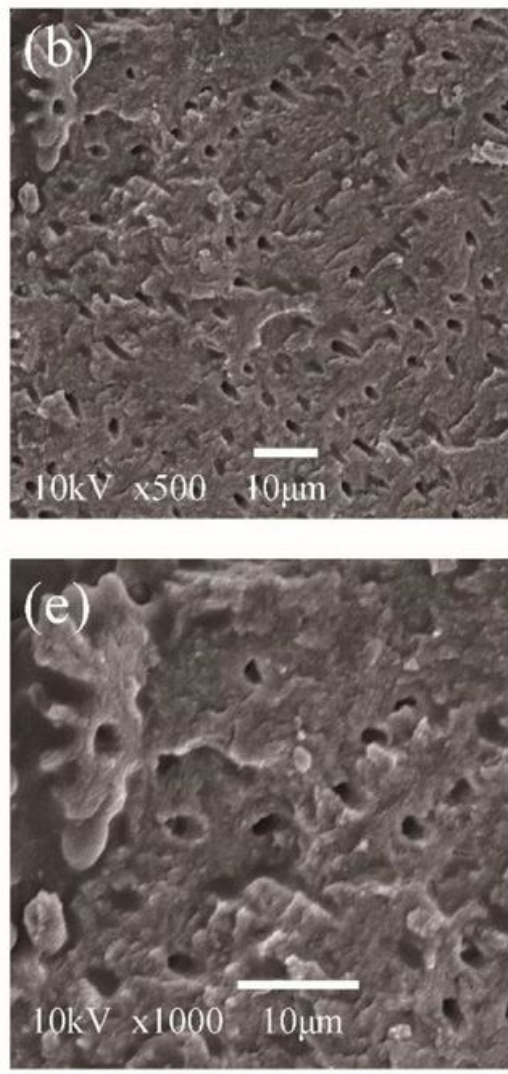

EA
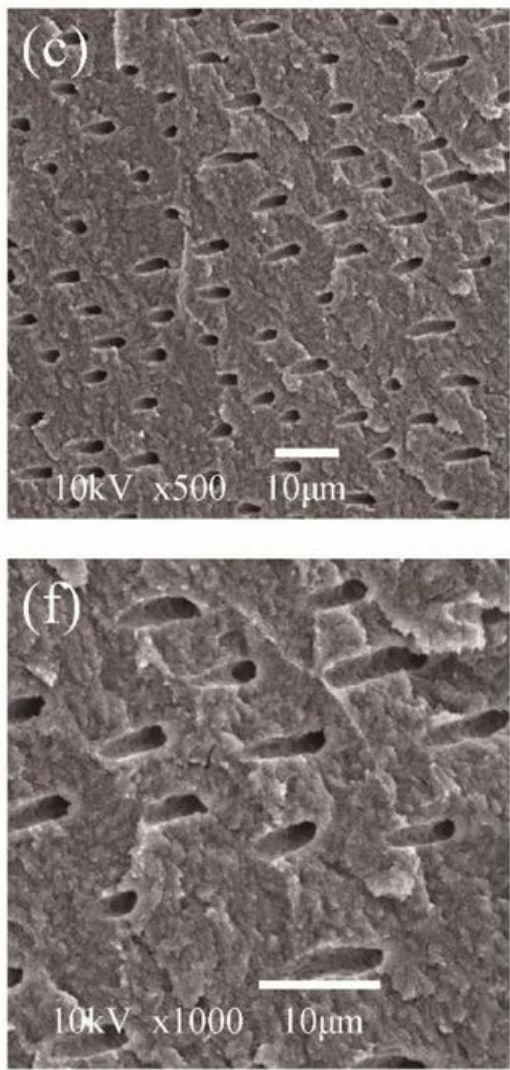

\section{Figure 3}

Representative SEM images of $\times 500$ and $\times 1000$ in the apical thirds in the (a, d) NI group, (b, e) PUI group, and (c, f) EA group. (SEM, scanning electron microscopy; NI, needle irrigation; PUI, passive ultrasonic irrigation; EA, Easydo Activator.) 